\title{
Internet Addiction or Excessive Internet Use
}

\author{
Aviv Weinstein, Ph.D. \\ Hadassah Medical Organization, Nuclear Medicine, Ein Kerem, Jerusalem, Israel
}

Michel Lejoyeux, Ph.D.

Hospital Bichat Claude Bernard, AP-HP, Psychiatry, Paris, France

\begin{abstract}
Background: Problematic Internet addiction or excessive Internet use is characterized by excessive or poorly controlled preoccupations, urges, or behaviors regarding computer use and Internet access that lead to impairment or distress. Currently, there is no recognition of internet addiction within the spectrum of addictive disorders and, therefore, no corresponding diagnosis. It has, however, been proposed for inclusion in the next version of the Diagnostic and Statistical Manual of Mental Disorder (DSM). Objective: To review the literature on Internet addiction over the topics of diagnosis, phenomenology, epidemiology, and treatment. Methods: Review of published literature between 2000-2009 in Medline and PubMed using the term "internet addiction. Results: Surveys in the United States and Europe have indicated prevalence rate between $1.5 \%$ and $8.2 \%$, although the diagnostic criteria and assessment questionnaires used for diagnosis vary between countries. Crosssectional studies on samples of patients report high comorbidity of Internet addiction with psychiatric disorders, especially affective disorders (including depression), anxiety disorders (generalized anxiety disorder, social anxiety disorder), and attention deficit hyperactivity disorder (ADHD). Several factors are predictive of problematic Internet use, including personality traits, parenting and familial factors, alcohol use, and social anxiety. Conclusions and Scientific Significance: Although Internet-addicted individuals have difficulty suppressing their excessive online behaviors in real life, little is known about the patho-physiological and cognitive mechanisms responsible for Internet addiction. Due to the lack of methodologically adequate research, it is currently impossible to recommend any evidence-based treatment of Internet addiction.
\end{abstract}

Keywords Behavioral addiction, excessive Internet use, Internet addiction

\section{INTRODUCTION}

\section{Problem Definition}

Problematic Internet use, or addiction, is characterized by excessive or poorly controlled preoccupations, urges or behaviors regarding Internet use that lead to impairment or distress.

Address correspondence to Dr. Aviv Malkiel Weinstein, Ph.D., Hadassah Medical Organization, Nuclear Medicine, Ein Kerem, Jerusalem, 91120, Israel; E-mail: avivweinstein@yahoo.com
The condition has attracted increasing attention in the popular media and among researchers, and this attention has paralleled the growth in computer use and Internet access (1). Phenomenologically, there appear to be at least three subtypes: excessive gaming, sexual preoccupations (cybersex), and e-mail/text messaging. Addicts may use the Internet for extended periods, isolating themselves from other forms of social contact, and focus almost entirely on the Internet rather than broader life events. In a sample of Italian adolescents, $36.7 \%$ showed signs of problematic Internet use. They used the Internet for many hours per week, mostly utilized dysfunctional coping strategies and showed worse interpersonal relations than peers who do not show signs of problematic Internet use (2). Others have suggested that Internet addiction can be explained by a need to escape from oneself and that may account for the excessive playing of Internet games (3).

There is considerable controversy with respect to diagnosis of Internet addiction and whether it ought to be included as a diagnosis entity in the Diagnostic and Statistical Manual of Mental Disorders, Fifth Edition (DSM V). Several impulse control disorders have been suggested to have similarities to substance addictions. These include pathological gambling and kleptomania. Computer/video game playing and Internet addiction have also been considered for inclusion in the forthcoming DSM V. This article reviews the evidence for similarities between Internet addiction and substance use disorders, their distinction from obsessive compulsive disorder, and identifies areas of uncertainty warranting future research. There are three different models proposed for Internet addiction (4). Some researchers have considered the impulse-control disorders as part of the obsessive-compulsive disorder spectrum a model. This model is supported by brain-imaging and pharmacological treatment studies with Selective Serotonin Reuptake Inhibitors (SSRIs) (although other treatments and brainimaging studies may challenge it). Secondly, the DSM V task force has decided to create a separate category of compulsive Internet usage disorder from the nonspecified impulse-control disorder (ICD-NOS). Thirdly, some psychiatrists have argued that Internet addiction should be included in the behavioral 
addiction spectrum, since it shows the features of excessive use despite adverse consequences, withdrawal phenomena, and tolerance that characterize many substance use disorders; however, there are little data bearing on these claims. It is not clear whether Internet addiction usually represents a manifestation of an underlying disorder, or is truly a discrete disease entity. The frequent appearance of Internet addiction in the context of numerous comorbid conditions raises complex questions of causality. It has been argued (5) that, based on the limited available data regarding course, prognosis, temporal stability, and response to treatment, it appears premature to consider Internet addiction as a discrete disease entity. However, growing research suggests that some individuals with Internet addiction are at significant risk and merit professional care and treatment. Carefully controlled studies are required to settle these controversies. This review searched articles published between 2000 and 2009 in Medline and PubMed, using the key word "Internet addiction" over the topics of diagnosis, phenomenology, epidemiology, and treatment.

\section{DIAGNOSIS AND PREVALENCE}

The diagnosis of Internet addiction (dependence) remains problematic. It does not appear in any official diagnostic system, including DSM-IV, and there are no widely accepted diagnostic criteria. Four components have been suggested as essential to the diagnosis (6): 1) excessive Internet use, often associated with a loss of sense of time or a neglect of basic drives, 2) withdrawal, including feelings of anger, tension, and/or depression when the computer is inaccessible, 3) tolerance, including the need for better computer equipment, more software, or more hours of use, and 4) adverse consequences, including arguments, lying, poor school or vocational achievement, social isolation, and fatigue.

There are currently no diagnostic instruments for Internet addiction that show adequate reliability and validity across countries. A recent systematic analysis of the various diagnostic instruments found that previous studies utilized inconsistent criteria to define Internet addicts, applied recruiting methods that may cause serious sampling bias, and examined data using primarily exploratory rather than confirmatory data analysis techniques to investigate the degree of association rather than causal relationships among variables (7). Thus, prevalence data on pathological Internet use are limited by methodological difficulties concerning the diagnosis and the heterogeneity of diagnostic instruments. This makes it difficult to compare prevalence rates across countries.

The questionnaires for diagnosis of Internet addiction have used items from substance dependence questionnaires, as well as new items related to Internet addiction. The most commonly used questionnaire is Young's Internet Addiction Scale (IAT) (cut off point score 70 and above), which has been validated in the United Kingdom (8), the United States (9), Finland (10), and Korea (11). The Chen Internet Addiction Scale (CIAS) has been widely used in Taiwan $(12,13)$. The Questionnaire of Ex- periences Related to Internet has been validated in Spain (14), the Compulsive Internet Use Scale (CIUS) in Holland (15), and the Problematic Internet Use Questionnaire (PIUQ) in Hungary (16). The assessment methods have been reviewed by Beard (17). The IAT was developed to help Internet addicts, those who are not sure if they are Internet addicted, and those who believe that they know someone who is pathologically using the Internet. The PIUS has the advantage of having 7 subscales of Internet addiction that were correlated with psychosocial health variables including: depression, loneliness, shyness, and selfesteem. These instruments are based on different theoretical underpinnings and do not agree on the underlying dimensions that make up problematic Internet use. Another criticism is that some items do not relate to addiction. There are also general concerns related to using self-reports, having dishonest answers, participants may not understand various questions or misinterpret the various test items. Additionally, there is also a problem of selection bias with the participant pool obtained from Web sites or undergraduate courses and no adequate control group. The use of a Web page may influence how people responded as well as the number of valid responses obtained. Finally, a person may show addictive behaviors toward one application, but not others.

International prevalence rates for Internet addiction using questionnaires such as the IAT range from $1.5 \%$ to $8.2 \%$ (18). In the United States, an online survey of 17,251 responders to a joint project with ABC-NEWS.com found that $6 \%$ of those surveyed met the criteria for Internet addiction (19). A recent random telephone survey of the general U.S. population reported an estimate of .3-.7\% (1). A study of Southern U.S. university students found that about a quarter met criteria for Internet dependence (20).

In Germany, an estimated 1.5 million people, i.e., $3 \%$ of the German population is believed to be at risk of Internet addiction (21). The rate of problematic Internet use in Italian adolescents was $5.4 \%$ (22). The prevalence of borderline Internet use in Greek adolescents was $12.8 \%$, while $10.4 \%$ of male excessive Internet users reported addictive Internet use (23). Using the Pathological Internet Use (PIU) scale in British students, 18.3\% were considered to be pathological Internet users (24).

Internet addiction has been most studied in the Far East. A Chinese study using the IAT scale found that, among responders aged 13 to 18 years, $10.2 \%$ used the Internet moderately and $.6 \%$ was severely addicted (25). Prevalence rates of Internet addiction range from $6.44 \%$ in Shaanxi Province in China (26) to between $2.4 \%$ and $5.52 \%$ in Hunan province in China $(27,28)$. Among Taiwanese university freshmen, $17.9 \%$ were addicted to the Internet (29). Among Korean middle school students, 16\% were potential at-risk users and 3.1\% were high-risk users (30). Other studies in Korea have found $4.3 \%$ (31), $10.7 \%$ (32), $20.3 \%$ (33), $1.6 \%$ (34), and 3.5\% (35) of adolescents diagnosed with Internet addiction. The main difficulty with these studies is that they use vague terms to describe levels of Internet use, such as "borderline," "excessive," "at risk," and "addictive," which are not operationally defined or clinically validated. The prevalence 
rates of Internet addiction have been examined elsewhere (12, 36).

\section{COMORBIDITY}

Cross-sectional studies on samples of patients report high comorbidity of Internet addiction with psychiatric disorders, such as affective disorders, anxiety disorders (including generalized anxiety disorder, social anxiety disorder), and attention deficit hyperactivity disorder (ADHD). It has been suggested (37) that the relationship between loneliness and preference for online social interaction is spurious and that social anxiety is the confounding variable.

German Internet-dependent students had a 78\% rate of comorbid depressive mood disorder and higher rates of impulsivity and depression (38). A higher percentage of anxiety disorder was found in a group of problematic Internet users compared with nonproblematic users of the Internet (39). Comorbidity with hypomania, dysthymia, obsessive compulsive personality disorder, borderline personality disorder, and avoidant personality disorder was found in U.S. adolescents (9). A combination of alexithymia, dissociative experiences, low self-esteem, and impulse dysregulation were suggested as-risk factors for Internet addiction in a sample of Italian adolescents (40). Male students in Finland had higher mean score on the IAT than women and subjects with cannabis use had higher mean score on the IAT compared to non-users (10). There was a significant association between Internet addiction and depressive symptoms in South Korean adolescents (33), along with high levels of depression and suicidal ideation (34).

Adolescents with Internet addiction had higher ADHD symptoms, depression, social phobia, and hostility in Taiwan (41). Higher ADHD symptoms, depression, and hostility are associated with Internet addiction in male adolescents, and only higher ADHD symptoms and depression are associated with Internet addiction in female students. Internet addiction and impulsivity were associated with adult ADHD, and the association between attention deficit and Internet addiction was more significant among female Taiwanese college students (42). Finally, an association was found between Internet addiction and harmful use of alcohol among Taiwanese students $(43,44)$. It is unknown whether Internet addiction and these comorbid disorders could be explained by shared risk factors or are best considered as secondary disorders.

\section{NEUROBIOLOGY AND BRAIN IMAGING}

Currently, there have been very few studies on the neurobiology of Internet addiction. There were reported studies on computer and videogame addiction (see Weinstein, elsewhere in this issue). Among the first brain imaging studies (13) has reported 10 participants with online gaming addiction who were presented with gaming pictures and the paired mosaic pictures while undergoing functional magnetic resonance imaging (fMRI) scanning. In the addicted group, right orbito-frontal cortex, right nucleus accumbens, bilateral anterior cingulate and medial frontal cortex, right dorsolateral prefrontal cortex, and right caudate nucleus were activated in contrast to the control group. The activation of the regions-of-interest (ROI) was positively correlated with self-reported gaming urge and recalling of gaming experience provoked by the pictures. The results demonstrated that the neural substrates of cue-induced gaming urge/craving in online gaming addiction was similar to that of the cue-induced craving in substance dependence. Thus, the results suggested that the gaming urge/craving in online gaming addiction and craving in substance dependence might share the same neurobiological mechanism.

\section{GENETIC FACTORS}

There is some evidence for genetic factors influencing Internet addiction. A Korean study (45) compared adolescents diagnosed with excessive Internet use with healthy control subjects on genetic polymorphisms of the serotonin transporter gene and with respect to novelty seeking and harm avoidance on Cloninger's Tridimensional Personality Questionnaire (TPQ). They found that the excessive Internet users had higher frequencies of the long-arm allele (SS-5HTTLPR), greater harm avoidance, and higher Beck Depression Inventory scores. SS5HTTLPR frequency was closely related to harm avoidance in excessive Internet users. This study suggested that subjects with excessive Internet use may have genetic and personality traits similar to depressed patients.

\section{WHY DO PEOPLE BECOME ADDICTED TO THE INTERNET?}

For addicted Internet users, their excessive behavior may serve as an (inadequate) stress coping strategy. A study of Internet-dependent children in Germany revealed patterns of watching television, communication, ability to concentrate in school lectures, and preferred strategies for coping with negative emotions that differed from other children (46).

The Internet may also be used as a forum for expanding social networks and, consequently, enhancing the chance of meaningful relationships, self-confidence, social abilities, and social support. Although those who primarily used the Internet for online chat believed that the Internet is psychologically beneficial to them, they also believed that frequent Internet users are lonely and that the Internet can be addictive. It is, therefore, argued that "chat" users who are socially fearful may be using the Internet as a form of low-risk social approach and an opportunity to rehearse social behavior and communication skills, which may help them improve interactions in face-to-face social environments (47).

Others have suggested that people with Internet dependence use the Internet as a coping mechanism against underlying psychological developmental issues; the fifth and sixth Eriksonian crises (identity, intimacy) were related to Internet dependence among Taiwanese college students (48). Students who were 
Internet-dependent scored significantly lower on most measures that reflected successful resolution of these crises, and scored higher on the measures that reflected unsuccessful resolution of these crises (48).

Compulsive cybersex has become a significant component of Internet addiction for many men and women who have fallen prey to the accessibility, affordability, and anonymity of online sexual behaviors (49). Some patients develop problems with compulsive cybersex due to predisposition or accidental conditioning experiences, while other compulsive users have underlying trauma, depression, or addiction. Both men and women with cybersex problems exhibit maladaptive coping, conditioned behavior, dissociative reenactment of life trauma, courtship disorder, intimacy dysfunction, and addictive behavior (49). The problematic Internet use group showed higher scores in the SelfDirectedness and Cooperativeness profiles and lower scores in the Novelty Seeking and Self-Transcendence profiles of the JTCI, compared with the nonproblematic Internet use group, after controlling for the ADHD symptoms.

These maladaptive coping mechanisms seem overlap with sexual addiction (see Thibaut elsewhere in this issue), but they are using the specific media of the Internet.

In the case of compulsive cybersex, the content of display, more specifically pornography, is a specific form of sexual computer-assisted behavioral addiction. Therapists report a growing number of patients addicted to this activity, a form of both Internet addiction and sexual addiction, with the standard problems associated with addictive behavior.

\section{FACTORS PREDICTIVE OF PROBLEMATIC INTERNET USE}

Several studies have examined the role of personality factors in excessive Internet use. Higher frequency of Internet use, lack of perseverance (an aspect of impulsivity), and online group membership significantly predicted problematic Internet use in Australian students (50). The personality dimension of psychoticism correlated positively with the constructs of harmonious and obsessive passion, and this was mediated by the tendency to express one's true self on the Internet in Turkish adolescents (51). South Korean Internet-addicted adolescents had more interpersonal problems than healthy users (30). Personality factors such as high harm-avoidance (HA), novelty seeking (NS), reward dependence (RD), low self-directedness, and low cooperativeness were positively correlated with Internet addiction in two South Korean studies $(33,52)$. However, there was contradictory evidence of high Self-Directedness and Cooperativeness profiles together with low scores on the Novelty Seeking and Self-Transcendence scales in another South Korean study (53). Internet addiction was positively associated with social anxiety and discontent with peer interactions (54), and with parenting attitudes, family communication, family cohesion, and family violence exposure (32).

In mainland China, potential risk factors for Internet addiction in adolescents were identified as being male, drink- ing behavior, family dissatisfaction, and experience of recent stressful events (25). Similar associations with adolescent Internet addiction were found in Taiwan, e.g., greater substance use experience, including friends or siblings with habitual alcohol drinking, low connectedness to school, high family conflict, low family function, perceived positive parental attitude towards adolescent substance use, and living in rural areas $(12,41)$. High NS, high HA, and low RD predicted a higher proportion of adolescents with Internet addiction, whereas high NS, low HA, and low RD predicted a higher proportion of adolescents with substance use (48).

\section{COGNITIVE FACTORS ASSOCIATED WITH PROBLEMATIC INTERNET USE}

Internet-addicted individuals may have difficulty suppressing their excessive online behaviors in real life. A study using the Iowa Gambling Task found that Internet-addicted individuals have deficits in decision-making function, chiefly a strategy learning lag rather than an inability to learn from task contingencies. They showed better performance on a Go/no-go task, suggesting some dissociation between mechanisms of decisionmaking and those of prepotent response inhibition (55).

A recent study has investigated the neurocognitive correlates of Internet addiction describing the characteristics of decision making (Iowa Gambling Task), potential to take risks (BART), and personality of college students with Internet addiction (56). The study has shown that the addicted students on the gambling task indicated better decision making, and performance on the BART indicated that they were not more likely to engage in risk-taking behaviors; and (d) TPQ scores showed lower reward dependence (RD) and higher novelty seeking (NS) for the addicts. Their higher performance on the Iowa gambling test differentiates the Internet addiction group from the substance use and pathologic gambling groups that have been shown to be deficient in decision making on the Iowa test.

\section{PROSPECTIVE STUDIES ON OUTCOME OF INTERNET ADDICTION}

Very little is known about factors associated with the outcome of Internet addiction. A prospective, population-based study evaluating the incidence and remission rates for Internet addiction and the associated predictive factors in Taiwanese adolescents found that the 1-year remission rate for Internet addiction was $49.5 \%$ (57). High exploratory excitability, low reward dependence, low self-esteem, low family function, and online game playing were associated with greater severity of the Internet addiction, while low hostility and low interpersonal sensitivity were associated with remission. A further two-year prospective study examined the predictive values of psychopathology for the occurrence of Internet addiction (58). Depression, ADHD, social phobia, and hostility were found to predict the occurrence of Internet addiction in the 2-year follow-up, and hostility and ADHD were the most significant predictors of Internet addiction in male and female adolescents, 
respectively. Finally, a study examined the associations between aggressive behaviors and Internet addiction and online activities in adolescents (59). The results demonstrated that after controlling for the effects of shared associated factors and watching violent TV programs, adolescents with Internet addiction were more likely to have aggressive behaviors during the previous year. The association was more significant among adolescents in junior high schools than in senior high/vocational schools. Online chatting, adult sex Web viewing, online gaming, online gambling, and Bulletin Board System were all associated with aggressive behaviors.

\section{HEALTH HAZARDS}

The known health hazards associated with Internet addiction appear related to sleep deprivation or disturbance. A South Korean study of high school students with Internet addiction found a $37.7 \%$ prevalence of excessive day time sleepiness, whereas the prevalence in possible Internet addicts and nonaddicts was $13.9 \%$ and $7.4 \%$, respectively. The prevalence of insomnia, witnessed snoring, apnea, teeth grinding, and nightmares was also higher in Internet addicts compared with possible addicts and non-addicts (60).

\section{INTERNET ADDICTION SUBJECTIVE EXPERIENCES AND DISABILITY}

Prior research explores the addictive qualities sustaining drug and alcohol abuse, pathological gambling, and even video game addiction; however, given the relative newness of Internet addiction, little is understood about the habit-forming nature of the Internet and its potential for abuse. As the Internet permeates our lives at home, school, and work, the Internet can create marital-, academic-, and job-related problems (61-63). A study of a small sample of adult Italian Internet addicts showed that the disease was felt to be strongly disabling, especially for family life (9).

A close look to the subjective experience during the Internet use would be helpful for distinguishing between pathological cases from just problematic. The Italian study has shown that dissociative symptoms were prominent and strongly related with measures of IAD severity, subjective disability, and OCD symptoms.

\section{TREATMENT}

Treatment for Internet addiction is based on interventions and strategies used in the treatment of substance use disorders. Psychosocial approaches are the mainstay of treatment, with very little study of pharmacological treatment. Due to the lack of methodologically adequate research, it is currently impossible to recommend any evidence-based treatment of Internet addiction (18).

There is preliminary evidence for success of an "initiated abstinence" program in 12-15 year old pupils in Austria, Germany, and Italy (64), and for a counseling program in Hong Kong (65).
Preliminary results from a study of 114 patients receiving $\operatorname{cog}$ nitive behavior therapy indicated that most clients were able to manage their presenting complaints by the eighth session, and symptom management was sustained at 6-month follow-up (66). There are no evidence-based treatments for Internet addiction. Cognitive behavioral approaches and psychosocial support may be helpful. Marital and family therapy may help in selected cases, and online self-help books and tapes are available. Lastly, a self-imposed ban on computer use and Internet access may be necessary in some cases (67).

There are media reports that unlicensed training camps in China are used to "wean" children, often in their teens, from overuse of the Internet, which has resulted in the death of at least one youth (68). In November 2009, the Chinese government banned physical punishment to "wean" teens from the Internet (69). A residential treatment center for pathological Internet use (ReSTART) has recently been established in Seattle, WA, but no outcome results are yet available.

Given that there is comorbidity between Internet addiction and other psychiatric disorders such as OCD and ADHD, several studies have used pharmacological agents that are designed to address the common mechanism. Others have identified the comorbidity with ADHD as the rationale for using methylphenidate in children with Internet video game addiction together with ADHD (11). A pharmacological open-label treatment study using extended release methylphenidate (mean dose $30.5+/-13.3 \mathrm{mg} / \mathrm{d}$, range $18-54 \mathrm{mg} / \mathrm{d}$ ), in 62 Korean children with Internet video game addiction and comorbid ADHD found that, after 8 weeks of treatment, measures of Internet use and Internet use duration were significantly reduced, and this improvement was positively correlated with improvement in measures of attention. These findings led the investigators to suggest that Internet video game playing might be a form of self-medication for children with ADHD.

Another study has identified the comorbidity of impulsivecompulsive Internet use with OCD to examine whether SSRIs such as Escitalopram can be useful for treatment of Internet addiction (71). A pharmacological open-label treatment study using Escitalopram (dose $10 \mathrm{mg} /$ day) with impulsive-compulsive Internet users showed significant decrease in the number of hours spent on the Internet during the first phase of treatment (week 1-10) but not later. Further placebo-controlled doubleblind studies are required.

\section{DISCUSSION}

Internet addiction, i.e., excessive use of the Internet with resulting adverse consequences, does not appear in any official diagnostic system, including DSM-IV. Block has argued that Internet addiction is a common disorder that merits inclusion in DSM-V (5). Conceptually, the diagnosis is a compulsive-impulsive spectrum disorder that involves online and/or offline computer usage. At least three subtypes have been identified: excessive gaming, sexual preoccupations, and 
e-mail/text messaging. All of the variants share the following four components: 1) excessive use, often associated with a loss of sense of time or a neglect of basic drives, 2) withdrawal, including feelings of anger, tension, and/or depression when the computer is inaccessible, 3) tolerance, including the need for better computer equipment, more software, or more hours of use, and 4) adverse consequences, including arguments, lying, poor achievement, social isolation, and fatigue. Others have argued that Internet addiction is not a true addiction and may be no more than a symptom of other, existing disorders such as anxiety, depression, ADHD or impulse control disorders (70). Little data are available to resolve this question, and the pathophysiological mechanisms underlying Internet addiction remain unknown. This relative ignorance also extends to treatment. The few published treatment studies for Internet addiction are based on interventions and strategies used in the treatment of substance use disorders. Thus, it is impossible to recommend any evidence-based treatment of Internet addiction.

\section{ACKNOWLEDGMENT}

A systematic literature review was conducted by means of PubMed using "Internet addiction" for electronic search, up to November 2009.

\section{Declaration of Interest}

Dr. Weinstein is now supported by the Israeli Anti-Drug Authority and the National Institute for Psychobiology in Israel. The authors report no conflicts of interest. The authors alone are responsible for the content and writing of the article.

\section{REFERENCES}

1. Shaw M, Black DW. Internet addiction: Definition, assessment, epidemiology and clinical management. CNS Drugs 2008; 22(5):353-365.

2. Milani L, Osualdella D, Di Blasio P. Quality of interpersonal relationships and problematic internet use in adolescence. Cyberpsychol Behav 2009; 12(6):681-684.

3. Kwon JH, Chung CS, Lee J. The Effects of Escape from Self and Interpersonal Relationship on the Pathological Use of Internet Games. Community Ment Health J 2009; Aug 23. [Epub ahead of print] DOI 10.1007/5 10597009-9236-1.

4. Dell'Osso B, Altamura C, Allen A, Marazziti D, Hollander E. Epidemiological and clinical updates on impulse control disorders: A critical review. Eur Arch Psychiatry Clin Neurosci 2006; 256:464-475.

5. Pies R. Should DSM-V designate "Internet Addiction" a mental disorder? Psychiatry (Edgmont) 2009; 6(2):31-37.

6. Block JJ. Issues for DSM-V: Internet Addiction. Am J Psychiatry 2008; 165:306-307.

7. Byun S, Ruffini C, Mills JE, Douglas AC, Niang M, Stepchenkova S, Lee SK, Loutfi J, Lee JK, Atallah M, Blanton M. Internet addiction: Metasynthesis of 1996-2006 quantitative research. Cyberpsychol Behav 2009; 12(2):203-207.

8. Widyanto L, McMurran M. The psychometric properties of the Internet addiction test. Cyberpsychol Behav 2004; 7(4):443-450.

9. Bernardi S, Pallanti S. Internet addiction: a descriptive clinical study focusing on comorbidities and dissociative symptoms. Compr Psychiatry 2009; 50(6):510-516.
10. Korkeila J, Kaarlas S, Jaaskelainen M, Vahlberg T, Taiminen T. Attached to the web - harmful use of the Internet and its correlates. Eur Psychiatry 2010; 25(4):236-241.

11. Han D, Lee Y, Na C, Ahn J, Chung U, Daniels M, Haws C, Renshaw $P$. The effect of methylphenidate on Internet video game play in children with attention-deficit/hyperactivity disorder. Compr Psychiatry 2009; 50(3):251-256.

12. Yen CF, Ko CH, Yen JY, Chang YP, Cheng CP. Multi-dimensional discriminative factors for Internet addiction among adolescents regarding gender and age. Psychiatry Clin Neurosci 2009; 63(3):357-364.

13. Ko CH, Liu GC, Hsiao S, Yen JY, Yang MJ, Lin WC, Yen CF, Chen CS. Brain activities associated with gaming urge of online gaming addiction. $J$ Psychiatr Res 2009; 43(7):739-747.

14. Beranuy Fargues M, Chamarro Lusar A, Graner Jordania C, Carbonell Sanchez X. Validation of two brief scales for Internet addiction and mobile phone problem use. Psicothema 2009; 21(3):480-485. (in Spanish)

15. Meerkerk GJ, Van Den Eijnden RJ, Vermulst AA, Garretsen HF. The Compulsive Internet Use Scale (CIUS): Some psychometric properties. $C y$ berpsychol Behav 2009; 12(1):1-6.

16. Demetrovics Z, Szeredi B, RÃzsa S. The three-factor model of Internet addiction: The development of the Problematic Internet Use Questionnaire. Behav Res Methods 2008; 40(2):563-574.

17. Beard KW. Internet Addiction: A review of current assessment techniques and potential assessment questions. Cyberpsychol Behav 2005; 8(1):7-14.

18. Petersen KU, Weymann N, Schelb Y, Thiel R, Thomasius R. Pathological Internet use-epidemiology, diagnostics, co-occurring disorders and treatment. Fortschr Neurol Psychiatr 2009; 77(5):263-271. (in German)

19. Greenfield DN. Psychological characteristics of compulsive Internet use: A preliminary analysis. Cyberpsychol Behav 1999; 2(5):403-412.

20. Fortson BL, Scotti JR, Chen YC, Malone J, Del Ben KS. Internet use, abuse, and dependence among students at a southeastern regional university. $\mathrm{J} \mathrm{Am}$ Coll Health 2007; 56(2):137-144.

21. Woelfling K, Buhler M, Lemenager T, Mairsen C, Mann K. Gambling and Internet addiction: Review and research agenda. Nervenarzt 2009; 80(9):1030-1039. (in German)

22. Pallanti S, Bernardi S, Quercioli L. The Shorter PROMIS Questionnaire and the Internet Addiction Scale in the assessment of multiple addictions in a high-school population: Prevalence and related disability. CNS Spectr 2006; 11(12):966-974.

23. Tsitsika A, Critselis E, Kormas G, Filippopoulou A, Tounissidou D, Freskou A, Spiliopoulou T, Louizou A, Konstantoulaki E, Kafetzis D. Internet use and misuse: A multivariate regression analysis of the predictive factors of Internet use among Greek adolescents. Eur J Pediatr 2009; 168(6):655-665.

24. Niemz K, Griffiths M, Banyard P. Prevalence of pathological Internet use among university students and correlations with self-esteem, the General Health Questionnaire (GHQ), and disinhibition. Cyberpsychol Behav 2005; 8(6):562-570.

25. Lam LT, Peng ZW, Mai JC, Jing J. Factors associated with Internet addiction among adolescents. Cyberpsychol Behav 2009; 12(5):551-555.

26. Ni X, Yan H, Chen S, Liu Z. Factors influencing Internet addiction in a sample of freshmen university students in China. Cyberpsychol Behav 2009; 12(3):327-330.

27. Deng YX, Hu M, Hu GQ, Wang LS, Sun ZQ. An investigation on the prevalence of Internet addiction disorder in middle school students of Hunan province. Zhonghua Liu Xing Bing Xue Za Zhi 2007; 28(5):445-448. (in Chinese)

28. Cao F, Su L, Liu T, Gao X. The relationship between impulsivity and Internet addiction in a sample of Chinese adolescents. Eur Psychiatry 2007; 22(7):466-471.

29. Tsai HF, Cheng SH, Yeh TL, Shih CC, Chen KC, Yang YC, Yang YK. The risk factors of Internet addiction-A survey of university freshmen. Psychiatry Res 2009; 167(3):294-299.

30. Seo M, Kang HS, Yom YH. Internet addiction and interpersonal problems in korean adolescents. Comput Inform Nurs 2009; 27(4):226-233. 
31. Jang KS, Hwang SY, Choi JY. Internet addiction and psychiatric symptoms among Korean adolescents. J Sch Health 2008; 78(3):165-171.

32. Park SK, Kim JY, Cho CB. Prevalence of Internet addiction and correlations with family factors among South Korean adolescents. Adolescence 2008; 43(172):895-909.

33. Ha JH, Kim SY, Bae SC, Bae S, Kim H, Sim M, Lyoo IK, Cho SC. Depression and Internet addiction in adolescents. Psychopathology 2007; 40(6):424-430.

34. Kim K, Ryu E, Chon MY, Yeun EJ, Choi SY, Seo JS, Nam BW. Internet addiction in Korean adolescents and its relation to depression and suicidal ideation: A questionnaire survey. Int J Nurs Stud 2006; 43(2):185-192.

35. Whang LS, Lee S, Chang G. Internet over-users' psychological profiles: A behavior sampling analysis on Internet addiction. Cyberpsychol Behav 2003; 6(2):143-150.

36. Ko C-H, Yen J-Y, Chen C-C, Chen S-H, Yen C-F. proposed diagnostic criteria of Internet addiction for adolescents. $J$ of Nervous and Mental Disease 2005; 193(11):728-733.

37. Caplan SE. Relations among loneliness, social anxiety, and problematic Internet use. Cyberpsychol Behav 2007; 10(2):234-242.

38. te Wildt BT, Putzig I, Zedler M, Ohlmeier MD. Internet dependency as a symptom of depressive mood disorders. Psychiatr Prax 2007; 34(Suppl 3): S318-322. (in German)

39. Kratzer S, Hegerl U. Is "Internet Addiction" a disorder of its own? — A study on subjects with excessive Internet use. Psychiatr Prax 2008; 35(2):80-83. (in German)

40. De Berardis D, D'Albenzio A, Gambi F, Sepede G, Valchera A, Conti CM, Fulcheri M, Cavuto M, Ortolani C, Salerno RM, Serroni N, Ferro FM. Alexithymia and its relationships with dissociative experiences and Internet addiction in a nonclinical sample. Cyberpsychol Behav 2009; 12(1): 67-69.

41. Yen JY, Ko CH, Yen CF, Wu HY, Yang MJ. The comorbid psychiatric symptoms of Internet addiction: Attention deficit and hyperactivity disorder (ADHD), depression, social phobia, and hostility. J Adolesc Health 2007; 41(1):93-98.

42. Yen JY, Yen CF, Chen CS, Tang TC, Ko CH. The association between adult ADHD symptoms and Internet addiction among college students: The gender difference. Cyberpsychol Behav 2009; 12(2):187-191.

43. Yen JY, Ko CH, Yen CF, Chen CS, Chen CC. The association between harmful alcohol use and Internet addiction among college students: Comparison of personality. Psychiatry Clin Neurosci 2009; 63(2):218224.

44. Ko CH, Yen JY, Yen CF, Chen CS, Weng CC, Chen CC. The association between Internet addiction and problematic alcohol use in adolescents: The problem behavior model. Cyberpsychol Behav 2008; 11(5):571576.

45. Lee Y, Han D, Yang K, Daniels M, Na C, Kee B, Renshaw P. Depression like characteristics of 5HTTLPR polymorphism and temperament in excessive Internet users. Journal of Affective Disorders 2009; 109(1):165-169.

46. Grusser SM, Thalemann R, Albrecht U, Thalemann CN. Excessive computer usage in adolescents-Results of a psychometric evaluation. Wien Klin Wochenschr 2005; 117(5-6):188-195. (in German)

47. Campbell AJ, Cumming SR, Hughes I. Internet use by the socially fearful: Addiction or therapy? Cyberpsychol Behav 2006; 9(1):69-81.

48. Ko CH, Yen JY, Chen CC, Chen SH, Wu K, Yen CF. Tridimensional personality of adolescents with Internet addiction and substance use experience. Can J Psychiatry 2006; 51(14):887-894.

49. Southern S. Treatment of compulsive cybersex behavior. Psychiatr Clin North Am 2008; 31(4):697-712.
50. Mottram AJ, Fleming MJ. Extraversion, impulsivity, and online group membership as predictors of problematic Internet use. Cyberpsychol Behav 2009; 12(3):319-321.

51. Tosun LP, Lajunen T. Why do young adults develop a passion for Internet activities? The associations among personality, revealing "true self" on the Internet, and passion for the Internet. Cyberpsychol Behav 2009; 12(4):401-406.

52. June KJ, Sohn SY, So AY, Yi GM, Park SH. A study of factors that influence Internet addiction, smoking, and drinking in high school students Taehan Kanho Hakhoe Chi 2007; 37(6):872-882. (in Korean)

53. Cho SC, Kim JW, Kim BN, Lee JH, Kim EH. Biogenetic temperament and character profiles and attention deficit hyperactivity disorder symptoms in Korean adolescents with problematic Internet use. Cyberpsychol Behav 2008; 11(6):735-737.

54. Liu CY, Kuo FY. A study of Internet addiction through the lens of the interpersonal theory. Cyberpsychol Behav 2007; 10(6):799-804.

55. Sun DL, Chen ZJ, Ma N, Zhang XC, Fu XM, Zhang DR. Decision-making and prepotent response inhibition functions in excessive Internet users. CNS Spectr 2009; 14(2):75-81.

56. Ko CH, Hsiao S, Liu GC, Yen JU, Yang MJ, Yen CF. The characteristics of decision making, potential to take risks, and personality of college students with Internet addiction. Psychiatry Res 2010; 175(1-2):121-125.

57. Ko CH, Yen JU, Yen CF, Lin HC, Yang MJ. Factors predictive for incidence and remission of Internet addiction in young adolescents: A prospective study. CyberPsychol Behav 2007; 10(4):545-551.

58. Ko CH, Yen JY, Chen CS, Yeh YC, Yen CF. Predictive values of psychiatric symptoms for Internet addiction in adolescents: A 2-year prospective study. Arch Pediatr Adolesc Med 2009; 163(10):937-943.

59. Ko CH, Yen JY, Liu SC, Huang CF, Yen CF. The associations between aggressive behaviors and Internet addiction and online activities in adolescents. J Adolesc Health 2009; 44(6):598-605.

60. Choi K, Son H, Park M, Han J, Kim K, Lee B, Gwak H. Internet overuse and excessive daytime sleepiness in adolescents. Psychiatry Clin Neurosci 2009; 63(4):455-462.

61. Young KS. Internet Addiction: A new clinical phenomenon and its consequences. American Behavioral Scientist 2004; 48(4):402-415.

62. Young KS. Caught in the Net. New York: John Wiley \& Sons, 1998.

63. Yellowlees PM, Marks S. Problematic Internet use or Internet addiction? Computers in Human Behavior 2007; 23(3):1447-1453.

64. Kalke J, Raschke P. Learning by doing: 'initiated abstinence', a schoolbased programme for the prevention of addiction. Results of an evaluation study. Eur Addict Res 2004; 10(2):88-94.

65. Shek DT, Tang VM, Lo CY. Evaluation of an Internet addiction treatment program for Chinese adolescents in Hong Kong. Adolescence 2009; 44(174):359-373.

66. Young KS. Cognitive behavior therapy with Internet addicts: Treatment outcomes and implications. Cyberpsychol Behav 2007; 10(5):671-679.

67. Shaw M, Black DW. Internet addiction: definition, assessment, epidemiology and clinical management. CNS Drugs 2008; 22(5):353-365.

68. Krajnak D. "China probe of abuse at Web addiction camp" CNN.Com/Asia. (Accessed 20 August 2009).

69. "China bans physical punishment for Internat addicts" Reuters India. (Accessed 11 November 2009).

70. Goldberg I. "Experts debate Internet addiction". http://www.physorg.com/ news82749930.html.

71. Dell' Osso B, Altamura AC, Hadley SJ, Baker BR, Hollander E. An openlabel trial of escitalopram in the treatment of impulsive-compulsive Internet usage disorder. European Neuropsychopharmacology 2007; 16:S82-S83. 
Copyright of American Journal of Drug \& Alcohol Abuse is the property of Taylor \& Francis Ltd and its content may not be copied or emailed to multiple sites or posted to a listserv without the copyright holder's express written permission. However, users may print, download, or email articles for individual use. 